\title{
Análise comparativa do ciclo de vida de materiais estruturantes construtivos em um pavilhão aviário
}

A indústria da construção civil é sinalizada como causadora de impactos severos ao meio ambiente. Diante deste cenário, o desafio é reduzir os agentes causadores de impactos ambientais. Uma forma de atingir resultados positivos nessa tarefa se dá pela substituição de insumos tradicionais, que, em sua maioria, apresentam alto impacto ao meio ambiente, sejam eles materiais de construção inovadores ou alternativos. A Análise do Ciclo de Vida (ACV) permite um diagnóstico sobre o processo produtivo de um produto, analisando não somente a utilização do material, como também toda sua cadeia produtiva, da extração da matéria-prima ao descarte. O objetivo desta pesquisa foi realizar uma análise comparativa do ciclo de vida do alumínio e do concreto como materiais estruturantes em um pavilhão aviário. O método adotado seguiu as recomendações das normas para ACV, as NBR ISO 14040 e 14044. Para a análise dos dados, foi utilizado o programa computacional OpenLCA versão 1.6.3 com a base de dados Ecoinvent versão 3.3, e, para a análise dos impactos, foram empregados os métodos CML e Demanda Cumulativa de Energia (CED). Dentro da fronteira do estudo, que compreende da produção do material ao local de construção, os resultados para a avaliação do inventário do alumínio provaram ser de menor impacto em relação ao concreto. Também foi analisado o uso de energia primária gasta durante o processo de produção com o alumínio e, mais uma vez, seus resultados mostraram menor impacto que o concreto.

Palavras-chave: Análise do Ciclo de Vida; Sustentabilidade; Edificações; OpenLCA; ISO 14040.

\section{Comparative analysis of the life cycle of constructive structural materials in an aviary building}

\begin{abstract}
The construction industry is flagged for causing severe impacts on the environment. Given this scenario, the challenge is to reduce the agents that cause environmental impacts. One way to achieving positive results is the replacement of traditional inputs, most of which, have a high impact on the environment, whether they are innovative or alternative building materials. Life Cycle Analysis (LCA) allows a diagnosis on the production process of a product, by analyzing its entire production chain, from raw material extraction to disposal. The objective of this research was to compare the structural use impacts between aluminum and concrete in a poultry house. The method followed the recommendations of the ISO 14040 and 14044 standards. Besides that, the research consists of utilizing OpenLCA version 1.6.3 for the impact calculations and the Ecoinvent 3.3 as database. For the impact analysis, both methods, CML and Cumulative Energy Demand (CED), were employed. Within the boundary of the study, which comprises the production of the material at the construction site, the results for aluminum evaluation inventory proved to have less impact then concrete's. The use of primary energy spent during the production process with aluminum was also analyzed and, once again, its results showed less impact than concrete.
\end{abstract}

Keywords: Life Cycle Analysis; Sustainability; Buildings; OpenLCA; ISO 14040

Topic: Uso de Recursos Naturais

Reviewed anonymously in the process of blind peer
Received: 03/01/2021

Approved: 28/01/2021

Ciro Andrade Siqueira (iD

Universidade Positivo, Brasil

http://lattes.cnpq.br/9799597221755036

http://orcid.org/0000-0003-4877-3136

ciro.andrade@gmail.com

Marco Aurélio da Silva Carvalho Filho (iD)

Universidade Positivo, Brasil

http://lattes.cnpq.br/3833309149531309

http://orcid.org/0000-0002-4143-787X

marco.filho@up.edu.br

Referencing this:

SIQUEIRA, C. A.; CARVALHO FILHO, M. A. S.. Análise comparativa do ciclo de vida de materiais estruturantes construtivos em um pavilhão aviário. Revista Ibero Americana de Ciências Ambientais, v.12, n.1, p.625-640, 2021. DOI: http://doi.org/10.6008/CBPC2179$\underline{6858.2021 .001 .0050}$ 


\section{INTRODUÇÃO}

Todo produto, independentemente de qual material é fabricado, traz impacto para o meio ambiente ao ser extraído, fabricado, utilizado e descartado (CHEHEBE, 1997).

Para a indústria de transformação, na concepção de um produto, podem existir várias opções de tecnologias e materiais. Projetistas e empresas têm, diante deste cenário de variabilidade de matéria-prima, a decisão da escolha por diversos fatores funcionais, estéticos e de sustentabilidade. Mesmo havendo uma disponibilidade de alternativas de materiais no mercado, cujos benefícios são conhecidos, como a redução de resíduos e o uso eficiente de energia, ainda são lentas as decisões de substituir um material por outro, por parte dos projetistas, devido à cultura de utilização de um determinado material a um específico produto. É, portanto, necessário difundir práticas para a avaliação e melhoria do meio ambiente (EVANGELISTA et al., 2018).

Na indústria da construção civil, seja qual for a dimensão da edificação, a utilização de materiais convencionais, como cimento e blocos cerâmicos, em seus sistemas construtivos é elevada. Apesar de existirem variedades de tecnologias para uma mesma finalidade construtiva de uma edificação, profissionais e empresas da construção civil tendem a manter a utilização desses materiais convencionais. É importante a avaliação dos aspectos do ciclo de vida de um produto deste setor com o propósito de conhecer o desempenho ambiental das construções (VINHAL, 2016).

A construção civil chega a consumir $40 \%$ da energia mundial produzida no seu processo de construção das edificações e chega a 50\% na emissão de gases neste processo. O desperdício de materiais também é alto, principalmente se não for tomado o cuidado no planejamento e no gerenciamento da obra. Além disso, uma edificação é um item de longa vida que exige uma manutenção constante como por exemplo, a energia gasta na iluminação e condicionamento de ar, e, portanto, o seu consumo energético continua sendo alto para a sua conservação depois de finalizada a sua construção (TAVARES, 2006).

Em 2018, foi realizada uma pesquisa pela WorldSteel, em parceria com o Instituto Aço Brasil e o Centro Brasileiro da Construção em Aço, sobre as características dos sistemas construtivos executados pelos projetistas e construtoras no Brasil. O resultado mostrou que a utilização do concreto e a alvenaria como sistemas construtivos em obras residenciais e comerciais é predominante no país. O estudo ainda apontou que o custo é o principal fator para a escolha de um sistema construtivo (CBCA, 2019).

A obtenção de alternativas na utilização ou no reuso de materiais na construção civil pode ter, como consequência, a redução de resíduos, o que ajuda a evitar desperdícios na execução de uma edificação e reduz os seus impactos ambientais, problema recorrente que é constantemente levantado para ser defrontado nas obras civis (USGBC, 2005).

A necessidade de ferramentas que possam analisar e estudar um material em todo o seu ciclo de vida, que consigam mensurar os seus impactos ambientais de maneira que, se tenham resultados que possam ser comparados e sirvam de indicadores é substancial para tomadas de decisões que resultem na escolha de materiais para a utilização em projetos de engenharia (MIYAZATO et al., 2009). 
A Análise do Ciclo de Vida (ACV) investiga as etapas, desde a extração da matéria-prima da natureza até a sua destinação final, bem como realiza a avaliação do impacto ambiental de um determinado material. É um método padronizado pela International Organization for Standardization - ISO, o que a torna um processo mundialmente aceito.

Nesse sentido, a ACV passou nos últimos anos a ganhar força como ferramenta para a mitigação dos impactos ambientais, o que se dá pela necessidade de resolver problemas ambientais ou também pela atenção às legislações ambientais (RASHID et al., 2015).

Assim sendo, uma análise do ciclo de vida de uma edificação é uma metodologia eficiente por poder fornecer dados para uma melhor comparação entre vários materiais e que podem ser alternativas na sua utilização, trazendo resultados mais consistentes na escolha de um material que cause o menor impacto ambiental. Estas informações são, nesse sentido, uma referência como dados comparativos e indicativos para os projetistas e envolvidos em um projeto de engenharia (BORGHI, 2013).

Esta pesquisa através da ferramenta da $\mathrm{ACV}$, compara a utilização do concreto e do alumínio sendo duas alternativas de matérias-primas como elemento estruturante na construção de um pavilhão aviário com a área de $2500 \mathrm{~m}^{2}$, construído no ano de 2016 na cidade de Rio Negrinho, Santa Catarina. Foi realizada a avaliação do impacto ambiental de um modelo do pavilhão com a sua estrutura e fechamento em alumínio e como comparação foi feita a mesma avaliação em um projeto idêntico com o sistema construtivo de prémoldados de concreto. $\mathrm{O}$ objetivo foi de identificar com quais destes materiais é possível diminuir o impacto ambiental da edificação.

\section{REVISÃO TEÓRICA}

\section{Análise do Ciclo de Vida}

A metodologia da Análise do Ciclo de Vida (ACV) examina um produto promovendo análises de impactos ambientais nos diversos estágios do seu ciclo de vida, passando pela extração, produção, utilização e pelo descarte, o que promove uma análise adequada desses impactos, e tem como resultados subsídios que permitem aos projetistas e empresas a melhor escolha de um material menos impactante ao ambiente. A ACV é, assim, uma importante ferramenta em decisões sobre a utilização de um determinado material (CHEHEBE, 1997).

A ACV leva em consideração todo o ciclo de vida de um material, ampliando a análise de impacto para o meio ambiente em toda a sua existência, como representa a Figura 1. Se estabelece com melhor precisão como os dados coletados podem contribuir para uma melhor análise de decisão na utilização de um determinado material (LIBRELOTTO et al., 2008).

Estudos sobre a ACV para o uso de materiais têm ocorrido para melhorias no processo de fabricação, como agilidade, diminuição de custos e redução de impactos ambientais (REPELE et al., 2015).

Um estudo de ACV em determinado material mapeia onde existe a maior demanda por energia, por exemplo, mostrando, dessa maneira, a causa e a possibilidade de alternativas nos processos fabris de um 
material. A ACV se coloca como uma fonte de informação e uma estratégia para execução de projetos, já que são comparados processos de fabricação de modo que se possa evitar altos consumos energéticos e minimizar a geração de resíduos (CARRE, 2011).

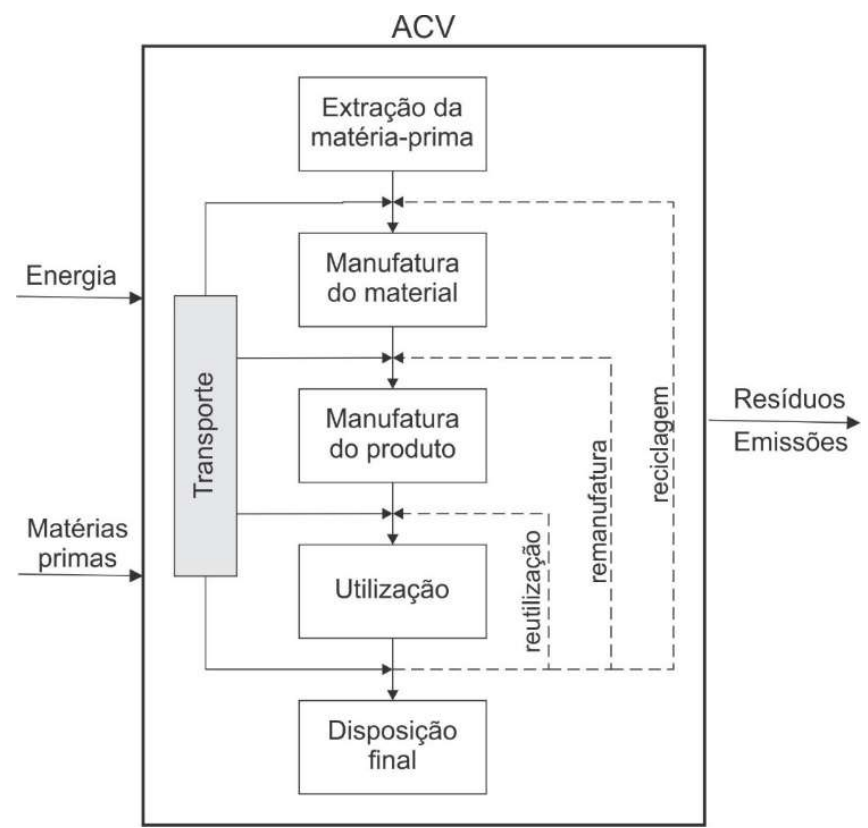

Figura 1: Representação esquemática da ACV. Fonte: Librelotto et al. (2008).

Ao se tratar de materiais de construção de edificações, a ACV tem contribuído para melhoras nos seus projetos. Em residências, por exemplo, o uso da água e da energia pode ser diminuído com a utilização de novas técnicas construtivas e novos materiais. A escolha de um material que será utilizado em um projeto traz, como consequência, menor impacto ao meio ambiente (HAMIDUL et al., 2015).

Materiais tradicionais, como o tijolo (bloco cerâmico de argila), têm no seu processo de fabricação um grande gasto de energia por meio de consumo de combustível fóssil. A substituição por fonte de energia como o biometano, por exemplo, também pode representar uma redução de até $50 \%$ no impacto ambiental (REPELE et al., 2015).

As tecnologias tradicionais de construção civil, apesar de serem utilizadas com muita frequência, têm, nos últimos anos, aumentado o uso de práticas inovadoras, chamadas de Métodos Modernos de Construção - MMC. Nesse meio, ganham destaque os materiais compósitos, que são aqueles formados por mais de uma matéria-prima, sendo que normalmente uma é um composto polimérico. De maneira ilustrativa, tem-se o uso do poliestireno expandido como exemplo, como um material que pode substituir vários insumos tradicionais como blocos cerâmicos e o concreto (MESAROS et al., 2015).

Entretanto, há uma ressalva: a indústria da construção civil é dependente de seus fornecedores, o que acarreta o fato de que, no cálculo de insumos e de energia, ela se torna uma grande geradora de impactos. Mas, muitas vezes, os dados desses insumos acabam por não serem computados já que dependem das informações que os fornecedores podem ter ou não. Nesses casos, inventários existentes nacionais de ACV podem contribuir para estudos mais precisos. No entanto, existem poucas bases de dados nacionais sobre os estudos de ACV, o que tem como consequência a utilização de bases internacionais. Portanto, 
quanto mais investigações ocorrerem que resultem em captação de bases nativas, melhor será a sustentação de padrões com características nacionais (SILVA, 2013).

Uma edificação é composta de três fases: pré-operacional, operacional e pós-operacional. A primeira é a sua construção, o consumo de materiais para a sua materialização. A segunda é sua ocupação e seu uso pelas pessoas, e o seu consumo energético para essas atividades. A terceira é quando a edificação deixa de ser utilizada e passa a ter o potencial de reciclagem ou reaproveitamento de seus materiais. Dessas três fases, a operacional é a que apresenta maior gasto energético devido ao fato de ser a mais longa fase, que é a duração em anos de utilização pelos seus habitantes (TAVARES, 2006).

Desse modo, o ciclo de vida de uma edificação é muito longo e não há como realizá-lo em apenas uma única investigação. Há a demanda de vários e constantes estudos para que se tenham dados que possam construir uma síntese mais geral de um edifício. Além disso, a particularidade de cada projeto de edificação traz uma necessidade de dados já levantados para que se possa utilizá-los como comparações e, dessa forma, trazer novas conclusões. Estudos já realizados podem servir como dados secundários para ajudar no encaminhamento para novas pesquisas sobre o assunto (BUENO, 2014).

O Instituto Brasileiro de Informação em Ciência e Tecnologia incentiva o desenvolvimento da ACV no Brasil como uma estratégia de dimensionar, de maneira mais competente, os impactos ambientais nacionais. Induz a promover a competência, o desenvolvimento da infraestrutura e de recursos tecnológicos para integração, socialização e produção da tecnologia em ACV (IBICT, 2019).

\section{Fases da Análise do Ciclo de Vida}

Conforme a NBR ISO 14040 (ABNT, 2009a), a ACV é a análise das entradas e saídas de um processo e a medição dos seus impactos ambientais durante o seu ciclo de vida. Conforme a Norma, a ACV se divide em quatro fases, como aparece na Figura 2.

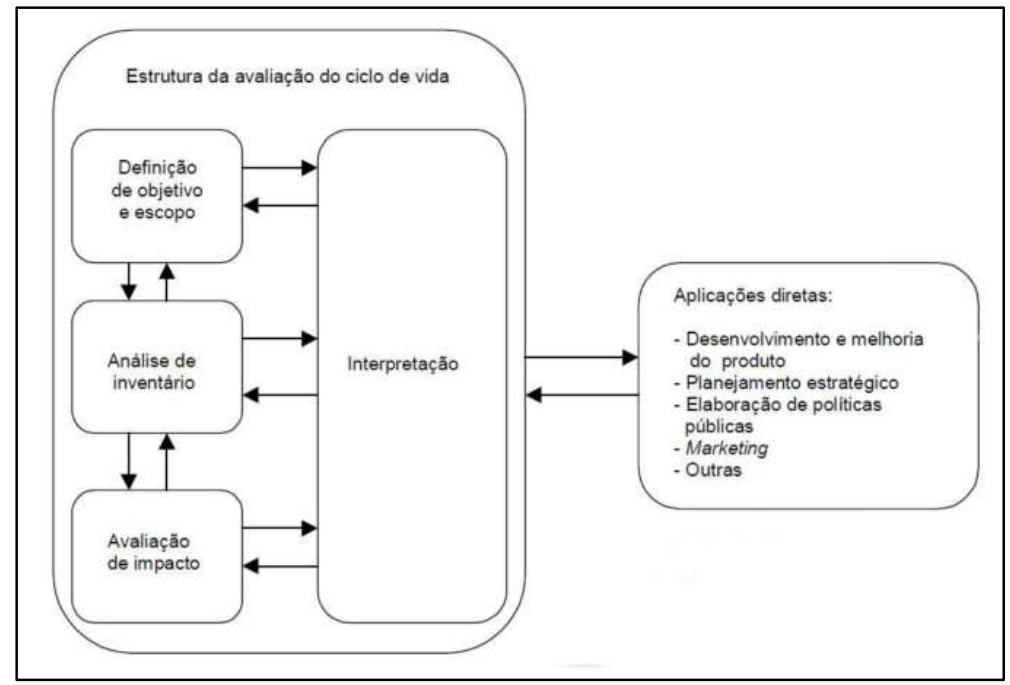

Figura 2: Fases de uma ACV NBR ISO 14040. Fonte: ABNT (2009a).

Fase 1: Objetivo e escopo, é a fase onde são definidos os objetivos do estudo - para quê e para quem ele está sendo feito e quais os resultados a que se desejam chegar com ele. No âmbito do escopo, são 
definidas as fronteiras do estudo. Como uma análise sobre um determinado material pode ser muito abrangente, é importante colocar os limites até onde devem ser interpretados os dados sobre ele.

Fase 2: Análise de inventário (Inventário de Ciclo de Vida - ICV), é a fase em que são coletados os dados para o estudo para a formação do inventário da ACV. Esses dados de entrada e saída serão quantificados para o sistema de um produto, podendo ser primários, dados coletados por quem faz a análise, ou secundários, baseados em dados de estudos já realizados, relatórios ou de outras bases de dados.

Fase 3: Avaliação de impacto (Avaliação de Impacto do Ciclo de Vida-AICV), é a fase de quantificação dos dados dos impactos ambientais. Por exemplo, pode-se classificar estes impactos como toxicidade humana, eutrofização, efeitos respiratórios, acidificação, entre outros.

Fase 4: Interpretação é a fase que procura qualificar os dados obtidos, proporcionando a quem desenvolve o estudo a obtenção de resultados conclusivos (ABNT, 2009a).

\section{MATERIAIS E MÉTODOS}

A pesquisa realizada tem natureza aplicada, com objetivos exploratórios e descritivos. A partir de observações de eventos e de perguntas do tipo de 'como?' e 'por quê?' (YIN, 2001), foram feitos levantamento bibliográfico, coleta e análise de dados em campo. Foram seguidos os protocolos da norma NBR ISO 14040, nas suas quatro fases citadas anteriormente.

O pavilhão aviário, foi construído utilizando o sistema de criação das aves chamado de 'dark house', que não apresenta aberturas de esquadrias, utilizando-se de iluminação e ventilação artificiais controladas. A iluminação é regulada por meio de lâmpadas, sendo possível controlar a intensidade da luz ao longo do dia. O objetivo deste processo é manter os animais mais calmos. O controle da ventilação e da temperatura é feito por meio de painéis evaporativos dispostos em uma das extremidades da edificação, com a finalidade de diminuir a temperatura na entrada do ar. Na outra extremidade do pavilhão, estão dispostos exaustores para a retirada do ar e manter uma menor amplitude térmica do ambiente (OLIVEIRA et al., 2012).

Normalmente, esse tipo de construção utiliza tecnologias e materiais tradicionais, como o concreto pré-moldado e fechamento em alvenaria ou ainda, em estrutura de aço com fechamento em painéis metálicos ou alvenaria. $\mathrm{O}$ pavilhão deste estudo (Figuras 3 e 4) foi projetado com estrutura e fechamento 100\% em alumínio, do tipo Alloy $6061 \mathrm{~T}$.

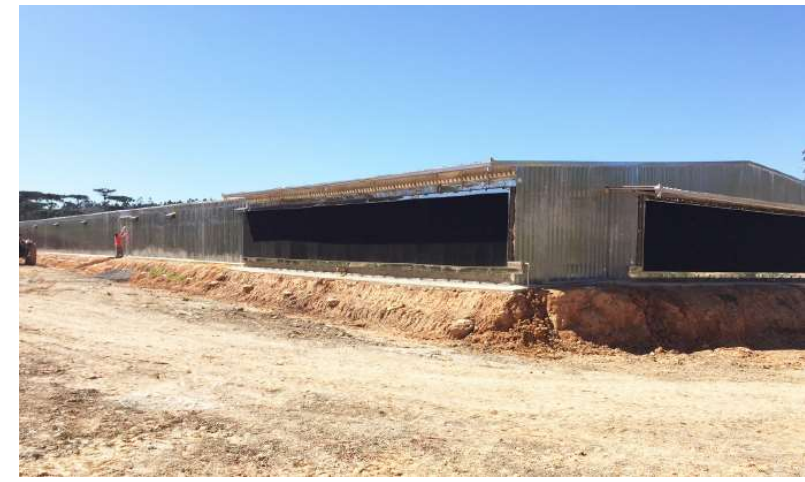

Figura 3: Pavilhão aviário em alumínio - vista externa.

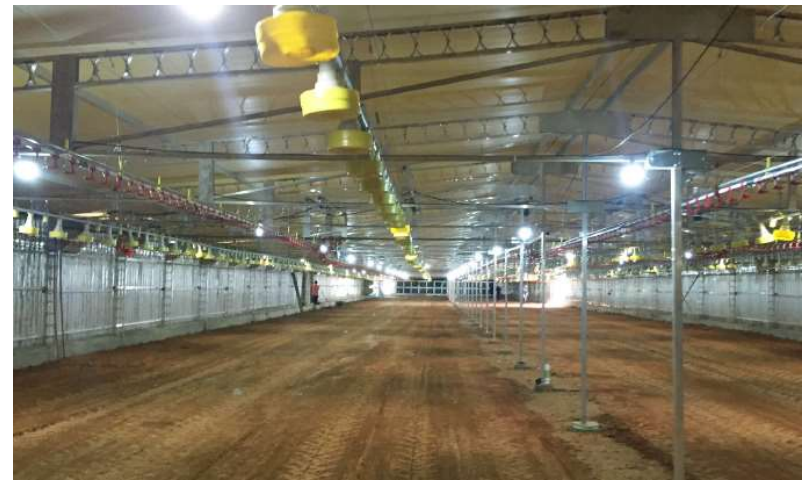

Figura 4: Pavilhão aviário em alumínio - vista interna. 
A partir da comparação de um projeto em concreto pré-moldado, todas as peças similares ao concreto, feitas em alumínio, foram projetadas e calculadas por se tratar de um projeto piloto e não haver no mercado nacional estrutura igual. O objetivo foi criar uma alternativa com o alumínio, obtendo o mesmo custo financeiro (por $\mathrm{m}^{2}$ ) que o projeto em concreto. Além disso, outros diferenciais também foram explorados, tais como a redução do tempo de execução da obra, a redução da quantidade de utilização de transporte do material, a diminuição de resíduos gerados e a potencialidade de reaproveitamento do material, no caso de desativação e desmonte do pavilhão. Por meio dos orçamentos dos materiais em ambos os projetos, foram levantados os dados quantitativos de materiais para a ACV dos dois modelos (concreto e alumínio) e, assim, pôde-se ter uma análise comparativa dos impactos ambientais entre as duas tecnologias.

\section{Escopo e fronteiras do estudo}

Esta pesquisa foi realizada com o levantamento da quantidade dos materiais e a sua utilização na etapa de construção do pavilhão aviário de acordo com as normas NBR ISO 14040 e NBR ISO 14044. Os componentes principais analisados foram as estruturas de sustentação, as estruturas da cobertura (tesouras), as telhas da cobertura e o fechamento (paredes). Estes componentes são os diferenciais entre cada um dos projetos. Elementos comuns em ambos os projetos, como fundações, equipamentos de ventilação, alimentação (comedouros) e esquadrias, não foram incluídos na análise, por se tratar dos mesmos materiais e não influenciarem nos resultados de forma comparativa.

Foram realizados dois levantamentos de inventários em separado, um para o pavilhão em concreto e outro para o pavilhão em alumínio. Com os resultados obtidos, se procedeu à análise de impactos, comparando os dois processos construtivos. As fronteiras do estudo delimitado para a coleta dos dados da análise dos materiais (alumínio e concreto) foram: extração das matérias-primas, fabricação do material e transporte, caracterizando o modelo 'berço a portão', demonstrado na Figura 5.

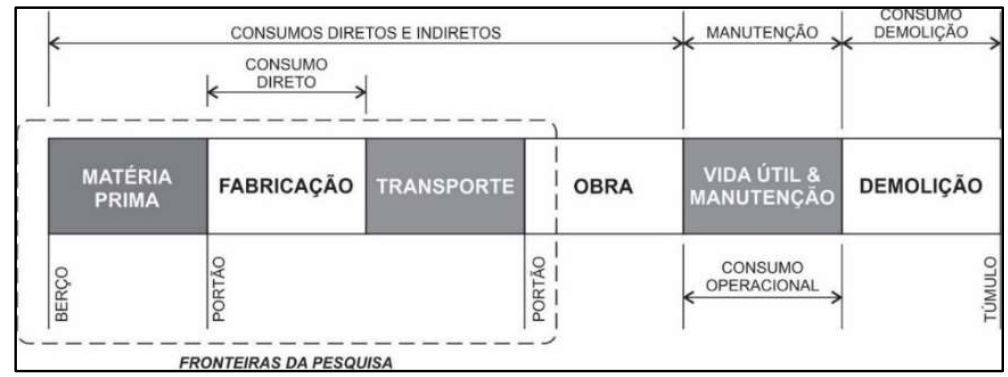

Figura 5: Fronteiras de berço a portão do estudo.

Simplificar mais o processo da ACV em edificações, com a delimitação de menores fronteiras, favorece a obtenção de dados mais precisos. Com isso, existe um foco maior nos materiais que mais podem causar impactos. Dividir uma ACV de uma edificação em vários estudos favorece a construção de dados com melhores resultados e facilita o entendimento pelos projetistas (SOUST-VERDAGUER et al., 2016).

Com o propósito do comparativo entre materiais diversos (ORTIZ et al., 2009), para a análise de inventário dos dados coletados, foi utilizada a versão 1.6.3 do programa computacional OpenLCA e a base de dados Ecoinvent versão 3.3, devido à confiabilidade e às características globais, sendo utilizadas em estudos 
científicos brasileiros (MORAGA, 2017). Na Figura 6, são expostos, de forma objetiva, os procedimentos metodológicos do estudo de ACV que foram adotados para esta pesquisa.

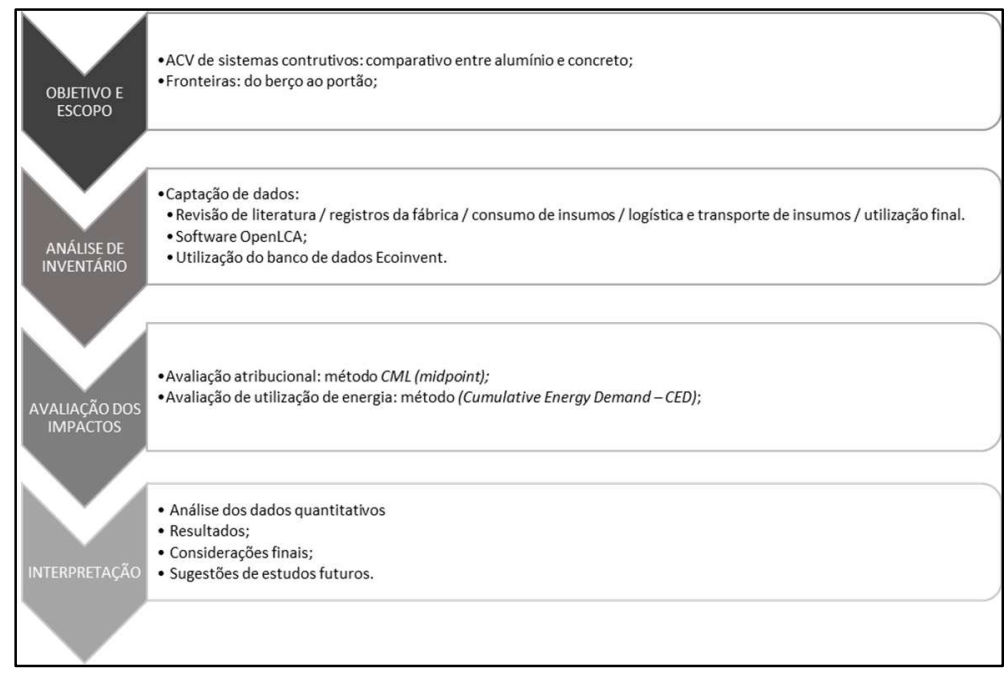

Figura 6: Fases da ACV realizadas neste estudo.

\section{Análise de inventário}

Os dados primários dos materiais foram quantificados na unidade funcional de massa $(\mathrm{kg})$ e volume $\left(\mathrm{m}^{3}\right)$. Estes dados quantitativos foram coletados por meio das especificações técnicas dos projetos e orçamentos do projeto do pavilhão aviário.

Esses dados foram relacionados às duas unidades funcionais definidas para que a formação do inventário (ICV) e a avaliação de impacto (AICV) pudessem apresentar uma completude esperada, como é estipulado pela norma NBR ISO 14044 (ABNT, 2009b). Mesmo no projeto de estrutura em alumínio, há a necessidade do uso do concreto para fundações, parte do fechamento e acabamento, mas em menores quantidades. O inventário do ciclo de vida (quantitativo dos materiais) coletado e utilizado na modelagem dos dois modelos (alumínio e concreto) é apresentado na Tabela 1.

Tabela 1: ICV de materiais dos pavilhões de concreto e de alumínio.

\begin{tabular}{llc}
\hline Componente & Unidade & Quantidade \\
\hline Pavilhão: Concreto & & \\
\hline Estrutura pré-moldada de concreto $30 \mathrm{Mpa}$ & $\mathrm{m}^{3}$ & 0,20 \\
Oitões (pilares e vigas) & $\mathrm{m}^{3}$ & 0,48 \\
Estrutura cooling (pilaretes e vigas) & $\mathrm{m}^{3}$ & 11,96 \\
Pórticos (pilares e tesouras) & $\mathrm{m}^{3}$ & $\mathbf{1 2 , 6 4}$ \\
Total & & \\
Paredes (fechamento) & $\mathrm{kg}$ & 3162,00 \\
Placas cimentícias & $\mathrm{kg}$ & 30030,00 \\
Tijolos de oito furos 11,5x19x19 cm & $\mathrm{kg}$ & 1300,00 \\
Cimento & $\mathrm{kg}$ & 3540,00 \\
Cal & $\mathrm{kg}$ & 24000,00 \\
Areia & & 3,12 \\
Contrapiso & $\mathrm{m}$ & 3 \\
Concreto desempenado polido 20 Mpa & & 7927,20 \\
Cobertura & $\mathrm{kg}$ & 940,50 \\
Terças em aço - viga U enrijecida & $\mathrm{kg}$ & 22458,00 \\
Poliestireno expandido - EPS (telhas) & $\mathrm{kg}$ & 324,00
\end{tabular}




\begin{tabular}{|c|c|c|}
\hline Tinta acrílica - interno e externo & $\mathrm{kg}$ & 324,00 \\
\hline \multicolumn{3}{|l|}{ Transporte } \\
\hline Caminhão truck - 7,5 a 16 ton de carga & $\mathrm{km}$ & 200 \\
\hline \multicolumn{3}{|l|}{ Pavilhão: Alumínio } \\
\hline \multicolumn{3}{|l|}{ Fundação } \\
\hline Blocos concreto 2 furos $(39 \times 9 \times 19 \mathrm{~cm})$ & $\mathrm{kg}$ & 11752,00 \\
\hline Aço de construção DN 13mm & $\mathrm{kg}$ & 162,00 \\
\hline \multicolumn{3}{|l|}{ Estrutura de alumínio } \\
\hline Treliças e terças & $\mathrm{kg}$ & 8000,00 \\
\hline \multicolumn{3}{|l|}{ Paredes (fechamento) } \\
\hline Telha de alumínio & $\mathrm{kg}$ & 2200,00 \\
\hline \multicolumn{3}{|l|}{ Contrapiso } \\
\hline Concreto desempenado polido $20 \mathrm{Mpa}$ & $\mathrm{m}^{3}$ & 3,12 \\
\hline \multicolumn{3}{|l|}{ Cobertura } \\
\hline Telha de alumínio & $\mathrm{kg}$ & 4000,00 \\
\hline \multicolumn{3}{|l|}{ Transporte } \\
\hline Caminhão truck - 7,5 a 16 ton de carga (alumínio) & $\mathrm{km}$ & 500 \\
\hline Caminhão truck - 7,5 a 16 ton de carga & $\mathrm{km}$ & 100 \\
\hline
\end{tabular}

Fonte: Empresa construtora

\section{Transporte do material}

O transporte do material estruturante, seguindo o itinerário da fábrica para o canteiro de obra, é uma etapa considerada relevante para o estudo de ACV (TAVARES, 2006). Para ambos os projetos, o meio de transporte da matéria-prima utilizado é um caminhão a diesel do modelo truncado (truck) de três eixos. A capacidade de carga deste modelo é de 7,5 a 16 toneladas. Para a ACV, foi escolhido o modelo Euro 5 (que corresponde ao modelo truncado), que é uma classificação para a quantidade de emissões dos motores. No Brasil, essa regulamentação foi criada pelo Conselho Nacional do Meio Ambiente - CONAMA, por meio do Programa de Controle da Poluição do Ar por Veículos Automotores - PROCONVE. O nível europeu Euro 5 é o que mais se equivale às especificações recomendadas de emissões pelo PROCONVE (BRASIL, 2011).

Para o projeto do pavilhão em concreto, a matéria-prima provém de fornecedores da região de Rio Negrinho, Santa Catarina e da região de Curitiba, Paraná. Isso determinou um raio de distância de até 100 km em transporte. Já para o pavilhão em alumínio, este material em específico foi produzido no município de Sorocaba, Estado de São Paulo, conduzido até Curitiba, onde foram montadas as estruturas e, então, transportadas para Rio Negrinho. Nesse caso, o alumínio obteve um raio de $500 \mathrm{~km}$ para o transporte, enquanto os demais materiais vieram de uma distância de $200 \mathrm{~km}$. No ICV dos materiais, foi utilizado, como unidade funcional de transporte, massa $(\mathrm{kg})$ ou volume $\left(\mathrm{m}^{3}\right)$ por quilômetro percorrido.

\section{Análise de impactos}

Para a avaliação dos impactos ambientais, foi utilizado o método CML baseline versão 4.4/2015, que realiza a análise do modelo atribucional. Esse método é confiável, consistente e atualizado, sendo utilizado globalmente para a ACV e é recomendado pela norma europeia EN 15804 (CEN, 2013). Esta norma determina as regras para a análise ambiental dos materiais da construção civil, sendo indicadas quais as categorias de impactos do modelo atribucional que devem ser analisadas no método CML. Na Tabela 2, são descritas essas categorias indicadas pela EN 15804, bem como as unidades funcionais, e que foram analisadas neste trabalho. 
Tabela 2: Categorias de AICV utilizadas (CEN, 2013).

\begin{tabular}{lll}
\hline Sigla & Categoria de impacto & Unidade \\
\hline GWP & Aquecimento global - Alterações climáticas & $\mathrm{kg} \mathrm{CO}{ }_{2}$ eq. \\
ODP & Depleção da camada de ozônio & $\mathrm{kg} \mathrm{CFC-11} \mathrm{eq.}$ \\
$\mathrm{AP}$ & Potencial de acidificação do solo e água & $\mathrm{kg} \mathrm{SO}_{2}$ eq. \\
EP & Eutrofização & $\mathrm{kg} \mathrm{PO}_{4}---e q$. \\
POCP & Oxidação fotoquímica & $\mathrm{kg} \mathrm{Etileno} \mathrm{eq.}$ \\
ADP nf & Depleção de recursos abióticos - elementos últimas reservas & $\mathrm{kg} \mathrm{Sb} \mathrm{eq.}$ \\
ADP f & Depleção de recursos abióticos - combustíveis fósseis & $\mathrm{MJ}$ \\
\hline
\end{tabular}

eq.: Equivalente

Além da recomendação pela norma EN 15804 (CEN, 2013), o método CML foi escolhido nesta pesquisa por ser um método utilizado com frequência quando existe o objetivo de escolher materiais e por apresentar resultados mais precisos e exatos. Além disso, tem uma validação global que atende à norma NBR ISO 14040 (BUENO, 2014).

As características principais do método CML são (ILCD, 2010): a. Suas categorias de impactos são descritas em artigos científicos; b. Tem fundamentação científica; c. Apresenta fatores alternativos para análises de cada fator de impacto; d. Diferenciação entre categorias básicas e específicas do estudo; e. Recomendação pela norma EN 15804 (CEN, 2013), que determina os princípios das declarações ambientais dos materiais da construção civil.

O método da Demanda de Energia Cumulativa (Cumulative Energy Demand - CED) também foi aplicado nesta pesquisa, devido ao alto consumo energético de uma edificação. Além disso, esse consumo não costuma ser calculado além das fronteiras do canteiro de uma obra, excluindo do cálculo energético o gasto de energia com a produção dos materiais (TAVARES, 2006). Esse método realiza a análise do uso da energia na produção de um material e na Tabela 3, é apresentada as categorias destes impactos do método.

Tabela 3: Demanda de energia primária (OpenLCA).

\begin{tabular}{ll}
\hline Método Demanda de Energia Cumulativa - CED & Unidade \\
\hline Categoria de impacto & $\mathrm{MJ}$ \\
\hline Recursos não renováveis - fóssil & $\mathrm{MJ}$ \\
Recursos não renováveis - nuclear & $\mathrm{MJ}$ \\
Recursos não renováveis - floresta primária & $\mathrm{MJ}$ \\
Recursos renováveis - biomassa & $\mathrm{MJ}$ \\
Recursos renováveis - geotérmica & $\mathrm{MJ}$ \\
Recursos renováveis - solar & $\mathrm{MJ}$ \\
Recursos renováveis - água & $\mathrm{MJ}$ \\
Recursos renováveis - vento & \\
\hline
\end{tabular}

\section{RESULTADOS E DISCUSSÃO}

Nesta etapa, obteve-se o resultado de cada uma das categorias dos impactos a partir dos dados analisados no inventário. Conforme as fronteiras definidas no estudo, a análise dos impactos considerou a extração, a produção e o transporte da matéria-prima a partir da sua retirada do meio ambiente até o canteiro de obra da edificação (berço-a-portão). Os resultados das análises comparativas pelo método CML são apresentados na Tabela 4.

Nos resultados do alumínio, as duas categorias com maiores impactos foram a depleção de recursos abióticos - combustíveis fósseis (ADP f) e o aquecimento global - alterações climáticas (GWP). Nestes indicativos, o alumínio acaba por ser mais impactante devido ao seu processo extrativo, por ter um alto 
consumo energético em seu processamento. O alumínio, na etapa inicial de obtenção da alumina a partir da bauxita, demanda um alto consumo de energia. Já nas etapas seguintes, o metal tem baixo consumo energético em comparação a outros processos industriais (OERS et al., 2016).

Tabela 4: Resultados da avaliação de impactos - Alumínio vs. Concreto (OpenLCA).

\begin{tabular}{llll}
\hline Método CML & & \\
\hline Categoria de impacto & ALUMíNIO & CONCRETO & Unidade \\
\hline Potencial de acidificação do solo e água & $9,12244 \mathrm{E}+01$ & $2,17703 \mathrm{E}+02$ & $\mathrm{~kg} \mathrm{SO}_{2}$ eq. \\
Aquecimento global - Alterações climáticas & $1,75395 \mathrm{E}+04$ & $6,51758 \mathrm{E}+04$ & $\mathrm{~kg} \mathrm{CO}_{2}$ eq. \\
Depleção de recursos abióticos - elementos últimas reservas & $5,07551 \mathrm{E}+00$ & $2,21932 \mathrm{E}-01$ & $\mathrm{~kg}$ antimônio eq. \\
Depleção de recursos abióticos - combustíveis fósseis & $1,54729 \mathrm{E}+05$ & $7,68972 \mathrm{E}+05$ & $\mathrm{MJ}$ \\
Eutrofização & $3,32953 \mathrm{E}+01$ & $7,57111 \mathrm{E}+01$ & $\mathrm{~kg}$ PO \\
Depleção da camada de ozônio & $1,11877 \mathrm{E}-03$ & $9,92856 \mathrm{E}-03$ & $\mathrm{~kg}$ CFC-11 eq. \\
Oxidação fotoquímica & $4,27438 \mathrm{E}+00$ & $1,95462 \mathrm{E}+01$ & $\mathrm{~kg}$ etileno eq. \\
\hline
\end{tabular}

eq.: Equivalente

No item de transporte, considerando que o modelo do caminhão foi o mesmo - modelo truncado (truck) de três eixos - o alumínio é menor em seus impactos, vantagem principalmente devida a seu peso. Por ser um material leve, não há a necessidade de ser transportado por caminhões de alta capacidade de carga. Além disso, a quantidade de viagens é menor para um volume do alumínio quando se compara a outros materiais como o concreto (CNI, 2017). Na Figura 7, tem-se graficamente o comparativo relativo entre as categorias de impactos do alumínio e concreto. O processo mais impactante é exibido como $100 \%$ e o segundo processo é comparado em relação ao primeiro.

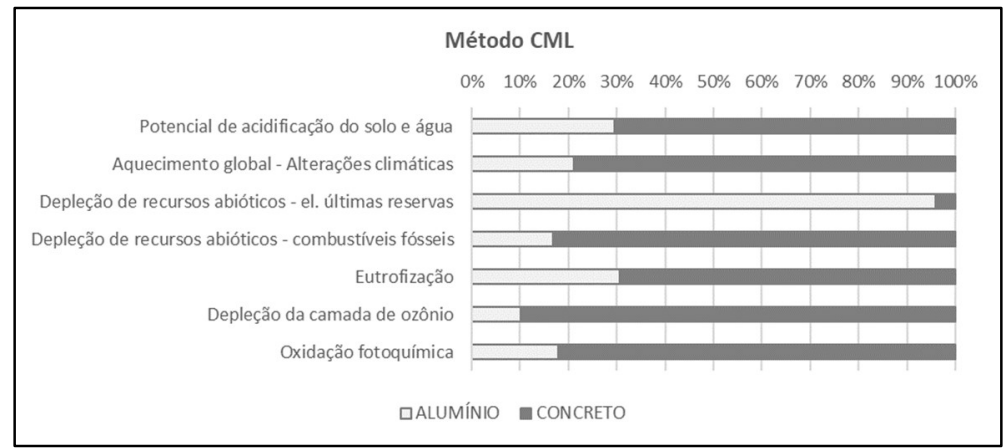

Figura 7: Comparativo de impactos - Alumínio vs. Concreto (OpenLCA).

Na Tabela 5, é apresentada a utilização do total de energia primária, fazendo o uso do segundo método de AICV, o da Demanda de Energia Cumulativa (CED) nos dois processos construtivos.

Tabela 5: Demanda de energia primária (OpenLCA).

\begin{tabular}{|c|c|c|c|}
\hline \multicolumn{4}{|l|}{ Método Demanda de Energia Cumulativa - CED } \\
\hline Categoria de impacto & ALUMÍNIO & CONCRETO & Unidade \\
\hline Recursos não renováveis - fóssil & $1,65945 E+05$ & $8,34627 E+05$ & MJ \\
\hline Recursos não renováveis - nuclear & $1,02432 E+04$ & $3,50109 E+04$ & MJ \\
\hline Recursos não renováveis - floresta primária & $2,02526 \mathrm{E}+01$ & $1,12786 \mathrm{E}+02$ & MJ \\
\hline Recursos renováveis - biomassa & $7,37261 E+03$ & $1,03760 E+04$ & MJ \\
\hline Recursos renováveis - geotérmica & $1,01873 \mathrm{E}+02$ & $2,93265 \mathrm{E}+02$ & MJ \\
\hline Recursos renováveis - solar & $2,36987 \mathrm{E}+00$ & $9,03967 \mathrm{E}+00$ & MJ \\
\hline Recursos renováveis - água & $9,00484 \mathrm{E}+03$ & $6,21104 \mathrm{E}+04$ & MJ \\
\hline Recursos renováveis - vento & $5,50365 \mathrm{E}+02$ & $3,30515 E+03$ & MJ \\
\hline
\end{tabular}

Nos resultados do alumínio e do concreto, as duas categorias com maiores impactos energéticos foram primeiramente os recursos não renováveis - fóssil e, em segundo, os recursos renováveis - água. Neste 
caso, a matriz hidrelétrica utilizada na produção do alumínio contribuiu para esses resultados. A pegada de carbono brasileira deste metal é uma das mais baixas mundialmente, cerca de $4,2 \mathrm{t}$ de $\mathrm{CO}_{2}$ equivalente por tonelada de alumínio, comparada com a média global de 9,7 de $\mathrm{CO}_{2}$ equivalente por tonelada de alumínio. Essa vantagem se deve ao emprego deste modelo de matriz energética (CNI, 2017).

Já o concreto utiliza matrizes fósseis na sua produção, em fornos para a produção do clínquer, e matrizes elétricas no seu maquinário de produção. Desse consumo, $80 \%$ da energia térmica ocorre com a queima de combustíveis fósseis para a produção do clínquer, tornando o processo um alto emissor de gases poluentes (BELATO, 2013).

O consumo energético na fabricação do material é um motivo importante para quando a sustentabilidade é um fator desejado em um empreendimento, o que se torna motivo para reflexão ao pesquisar materiais que serão utilizados em um projeto de edificações (PIEROBON et al., 2019).

Na Figura 8, graficamente é apresentado o resultado da utilização da energia pelos dois processos construtivos, do processo mais impactante em relação ao menor.

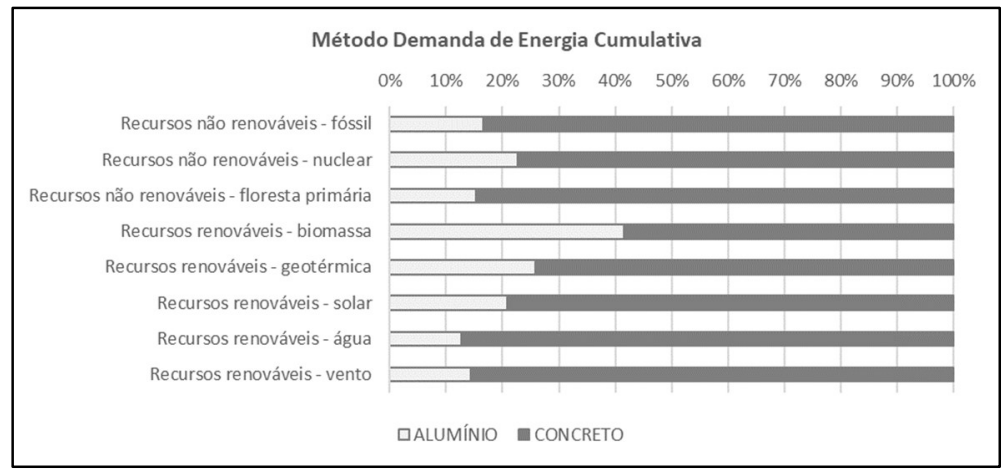

Figura 8: Comparativo do uso de energia primária (OpenLCA).

Conforme os resultados, o sistema construtivo do concreto é mais impactante em todas as matrizes energéticas em comparação ao sistema do alumínio.

O calor interno do pavilhão, quando em funcionamento, é uma preocupação dos criadores para com a saúde das aves. Temperatura, umidade e ventilação do ambiente afetam diretamente o desenvolvimento dos animais, inclusive podendo levá-las à morte. Caso não haja conforto térmico, pode-se causar estresse para a ave e queda no desempenho de criação. Como neste modelo de edificação de criação de aves - dark house, a ventilação é controlada por meio de painéis evaporativos e exaustores, sendo que a cobertura tem o papel fundamental nas trocas de calor entre os meios interno e externo, sendo o elemento principal do desempenho térmico do pavilhão (OLIVEIRA et al., 2015).

Fundamentado neste estudo de Oliveira et al. (2015), no qual também foi utilizado o alumínio como material para o telhado, o projeto do pavilhão do presente estudo usou, como cobertura, telhas duplas em alumínio, com uma camada de poliestireno expandido entre elas para melhor isolamento térmico. Além destes aspectos, o alumínio tem a propriedade física de alta reflexão (acima de 80\%) dos raios solares (ABAL, 2019). A partir do exposto, nota-se que estas características fazem do modelo do pavilhão em alumínio apropriado para a criação de aves, obtendo bom desempenho no requisito de conforto térmico. 
Este cenário é importante ao se observar que o consumo de energia é diretamente afetado pelo desempenho térmico da edificação, uma vez que, para o controle de temperatura do pavilhão, é necessário o uso de energia elétrica para exaustores e aquecedores. Portanto, a escolha do material interfere diretamente no consumo energético de uma edificação durante sua utilização (TAVARES, 2006). Estudos futuros como o desempenho energético do pavilhão aviário durante a sua utilização, podem colaborar com a afirmativa de como a escolha de materiais, pode diminuir os seus impactos ambientais.

Os três maiores resultados de impactos na utilização do concreto foram o aquecimento global, a depleção da camada de ozônio e a depleção de recursos abióticos (combustíveis fósseis), e que são recorrentes em edificações de alvenaria. O material cerâmico é apresentado como alto gerador desses impactos, pelo uso do concreto e por estar presente em grande parte dos revestimentos da edificação. Além disso, a manutenção desses materiais cerâmicos, na fase de utilização da edificação, eleva os resultados dos impactos na etapa operacional de uma construção (EVANGELISTA et al., 2018).

Nesta pesquisa, observou-se que os modelos de energia renováveis são os que têm melhor desempenho nas alterações climáticas, sendo que o modelo solar é o menos impactante para ambos os processos construtivos: 2,37 MJ para o alumínio e 9,04 MJ para o concreto. Apesar disso, a energia solar no Brasil ainda não é explorada de maneira condizente como potencial energético do país (KEMERICH et al., 2016).

Outro ponto observado neste estudo é que, comparado ao concreto, o alumínio é o elemento mais impactante quando se trata da sua extração dos meios naturais. Apesar disso, o alumínio é um material de alto reaproveitamento e reciclagem, o que pode contribuir de maneira satisfatória para a mitigação dos impactos que pode causar (PEREIRA et al., 2016). No caso deste estudo em específico, na hipótese de desmontagem do pavilhão em alumínio, a sua estrutura pode ser até $100 \%$ reaproveitada, situação mais incerta no caso do concreto. A escolha de materiais que tenham um potencial de reaproveitamento é um indicativo a ser considerado quando se pensa na etapa pós-operacional de uma edificação.

O Brasil é o décimo primeiro produtor mundial de alumínio primário. No processo de reciclagem do alumínio, uma vantagem é que o consumo para este processo é de $5 \%$ da energia gasta em relação à quando se obtém o metal primário a partir do minério (ABAL, 2019). Isso mostra que a escolha por materiais que tenham alta capacidade de reaproveitamento, se consome menos energia, melhorando o desempenho ambiental das edificações (EVANGELISTA et al., 2014).

Em estudos de ACV de edificações, o concreto, o aço e a alvenaria (tijolos e telhas) se mostram com frequência como materiais de elevado índice de impacto ambiental. Com os resultados, este presente estudo pretende contribuir com as possibilidades de substituição desses materiais, em sua totalidade ou de forma parcial, nos projetos de edificações. Como o concreto e a alvenaria são sistemas construtivos predominantes no Brasil, análises que possam indicar esses indicativos de mudanças, são importantes para orientar projetistas e construtoras (EVANGELISTA et al., 2018).

A falta de métodos que envolvam critérios mais padronizados na construção civil no Brasil, como transporte, consumo de água e energia e destinação de resíduos, representa obstáculos na aplicação da 
ferramenta da $\mathrm{ACV}$, pois os dados para a análise de inventário podem ser estimados e não muito precisos. Portanto, resultados de ACV sobre materiais para construção de edificações são fundamentais para disseminar essa ferramenta, contribuindo para a melhoria do meio ambiente (EVANGELISTA et al., 2018).

Destaca-se que, para auxiliar um estudo de ACV, o BIM (Building Information Modeling) é uma ferramenta que apresenta uma crescente utilização em projetos arquitetônicos e é útil para determinar o quantitativo da entrada de materiais na construção de uma edificação, contribuindo para a coleta do inventário de uma ACV. A utilização do BIM nas etapas de pré-operação, operação e pós-operação é demonstrada como uma ferramenta aliada aos estudos de ACV, fazendo-as ter respostas mais precisas (SOUST-VERDAGUER et al., 2016).

Os resultados do presente estudo demonstram que, quando a avaliação de impactos é um fator de importância determinado pelos projetistas e construtores, a escolha dos materiais de construção um projeto é fator determinante no desempenho ambiental das edificações.

\section{CONCLUSÕES}

O desenvolvimento de novas tecnologias híbridas de sistemas construtivos pode apresentar melhores resultados ambientais produzidos pelas edificações. Quando há a escolha de um material em relação a outro, que tem as mesmas características técnicas para a utilização em um projeto, mas existe o diferencial de ser menos impactante, causa-se, como resultado, uma construção mais sustentável.

A ACV é uma ferramenta eficiente em analisar a utilização de um material em relação a seu comportamento ambiental, e acaba sendo um critério confiável na seleção das alternativas. Apesar das pesquisas de ACV em edificações se tornarem frequentes em estudos científicos, é pouca a utilização da ferramenta pelos projetistas e construtoras brasileiras em suas tomadas de decisões, ou até mesmo a ferramenta é por eles desconhecida.

Este estudo procurou contribuir para a difusão e o fortalecimento da ACV no ambiente da indústria da construção civil como ferramenta para tomada de decisões de projeto. Ainda, busca incentivar a reflexão sobre os materiais de construção e como eles podem impactar o meio ambiente e, desse modo, melhorar o desempenho sustentável das edificações.

\section{REFERÊNCIAS}

ABAL. Associação Brasileira do Alumínio. Sustentabilidade: reciclagem no Brasil. São Paulo: ABAL, 2019.

ABNT. Associação Brasileira de Normas Técnicas. NBR ISO 14040: Gestão ambiental: Avaliação do ciclo de vida: Princípios e estrutura. Rio de Janeiro: 2009a.

ABNT. Associação Brasileira de Normas Técnicas. NBR ISO 14044: Gestão ambiental: Avaliação do ciclo de vida: Requisitos e orientações. Rio de Janeiro: 2009b.

BELATO, M. N.. Análise da Geração de poluentes na produção de cimento Portland com o coprocessamento de resíduos industriais. Dissertação (Mestrado) - Universidade
Federal de Itajubá, Itajubá, 2013.

BORGHI, A. D.. LCA and communication: environmental product declaration. The International Journal of Life Cycle Assessment, n.18, p.293-295, 2013. https://doi.org/10.1007/s11367-012-0513-9

BRASIL. Ministério do Meio Ambiente. Programa de controle da poluição do ar por veículos automotores - Proconve. Brasília: IBAMA, 2011.

BUENO, C.. Avaliação de ciclo de vida na construção civil: análise de sensibilidade. Tese (Doutorado em Arquitetura e Urbanismo) - Universidade de São Paulo, São Paulo, 2014. 
CARRE, A.. A Comparative life cycle assessment of alternative constructions of typical australian house design. Melbourne: Forest \& Wood Products Austrália, 2011.

CBCA. Centro Brasileiro da Construção em Aço. Estudo de sistemas construtivos nas obras brasileiras. Rio de Janeiro: Instituto Aço Brasil, 2019.

CEN. European Committee for Standardization. EN 15.804:2012+A1:2013: Sustainability of construction works: Environmental product declarations: Core rules for the product category of construction products. Luxemburg: Publications Office of the European Union, 2013.

CHEHEBE, J. R.. Análise do ciclo de vida de produtos: ferramenta gerencial da ISO 14000. Rio de Janeiro: Qualitymark, 1997.

CNI. Confederação Nacional da Indústria. A sustentabilidade da indústria brasileira do alumínio. Associação Brasileira do Alumínio. Brasília: CNI, 2017.

EVANGELISTA, P. P. A.; KIPERSTOK, A.; TORRES, E. A.; GONÇALVES, J. P.. Environmental performance analysis of residential buildings in Brazil using life cycle assessment (LCA). Construction and Building Materials, v.169, p.748761, 2018. DOI:

https://doi.org/10.1016/i.conbuildmat.2018.02.045

EVANGELISTA, P. P. A.; SOUZA, H. H. S.; TORRES, E. A.; GONCALVES, J. P.. Desempenho ambiental de edificações: Avaliação de ciclo de vida em empreendimento residencial. In: ENCONTRO NACIONAL DE TECNOLOGIA DO AMBIENTE CONSTRUÍDO, 15. Anais. Maceió, 2014. DOI: https://doi.org/10.17012/entac2014.183

HAMIDUL, I.; JOLLANDS, M.; SETUNGE, S.; HAQUE, N.; BHUIYAN, M.. Life cycle assessment and life cycle cost implications for roofing and floor designs in residential buildings. Energy and Buildings, v.104, p.250-263, 2015. DOI: https://doi.org/10.1016/i.enbuild.2015.07.017

IBICT. Instituto Brasileiro de Informação em Ciência e Tecnologia. Recomendação de modelos de Avaliação de Impacto do Ciclo de Vida para o Contexto Brasileiro. Brasília: IBICT, 2019.

ILCD. International Reference Life Cycle Data System Handbook. General guie for Life Cycle Assessment: Detailed guidance. European Commission - Joint Research Centre Institute for Environment and Sustainability. EUR 24708 EN. Luxembourg: Publications Office of the European Union, 2010.

KEMERICH, P.; FLORES, C. E. B.; BORBA, W. F.; SILVEIRA, R. B.; FRANÇA, J. R.; LEVANDOSKI, N.. Paradigmas da energia solar no Brasil e no mundo. Revista Eletrônica em Gestão, Educação e Tecnologia Ambiental, Santa Maria, v.20, n.1, p.241-247, 2016. DOI: https://doi.org/10.5902/2236117016132

LIBRELOTTO, D.; JALALI, S.. Aplicação de uma ferramenta de análise do ciclo de vida em edificações residenciais: estudo de caso. Guimarães: Universidade do Minho, 2008.

MESAROS, P.; SPISAKOVA, M.; KYJAKOVA, L.; MANDICAK, T.
Expanded polystyrene as the bearing building material of low energy construction. Materials Science and Engineering, v.71, p.012002, 2015. DOI: https://doi.org/10.1088/1757$899 x / 71 / 1 / 012002$

MIYAZATO, T.; OLIVEIRA, C. T. A.. Avaliação do Ciclo de Vida (ACV): aplicações e limitações no setor da Construção Civil. In: ENCONTRO NACIONAL, 5; ENCONTRO LATINOAMERICANO SOBRE EDIFICAÇÕES E COMUNIDADES SUSTENTÁVEIS, 3. Anais. Recife, 2009.

MORAGA, G. L.. Avaliação do ciclo de vida e simulação termoenergética em unidade habitacional unifamiliar do Programa Minha Casa Minha Vida. Dissertação (Mestrado em Engenharia Civil) - Universidade Federal do Rio Grande do Sul, Porto Alegre, 2017.

OERS, L. V.; GUINÉE, J.. The abiotic depletion potential: Background, Updates and future. Resources, v.5, n.1, p.16, 2016. DOI: https://doi.org/10.3390/resources5010016

OLIVEIRA, F. G.; GODOI, W.; PASSINI, R.. Environment in poultry production covered with thermal and aluminum roofing tiles. Journal of the Brazilian Association of Agricultural Engineering, Jaboticabal, v.35, n.2, p.206-214, 2015. DOI: https://doi.org/10.1590/1809-4430eng.agric.v35n2p206-214/2015

OLIVEIRA, P. A. V.; FILHO, J. I. S.; BELLAVER, P.; SCHEUERMANN, G. N.; CARON, L.. Estimativa da emissão de gases de efeito estufa na produção de frangos de corte nos sistemas convencional e dark house. Comunicado Técnico n. 504. Concórdia: EMBRAPA, 2012.

ORTIZ, O.; CASTELLS, F.; SONNEMANN, G.. Sustainability in the construction industry: A review of recent developments based on LCA. Construction and Building Materials, v.23, p.28-39, 2009. DOI: https://doi.org/10.1016/j.conbuildmat.2007.11.012

PEREIRA, T. N. D.; MILANEZ, B.; MOREIRA FILHO, R. M.; NOGUEIRA, F. M. A.. A reciclagem de alumínio no Brasil e o mercado internacional: uma análise quantitativa.

Planejamento e Políticas Públicas, v.47, p.289-303, 2016.

PIEROBON, F.; HUANG, M.; SIMONEN, K.; GANGULY, I.. Environmental benefits of using hybrid CLT structure in midrise nonresidential construction: an LCA based comparative case study in the U.S. Pacific Northwest. Journal of Building Engineering, v.26, 2019. DOI: https://doi.org/10.1016/j.jobe.2019.100862

RASHID, A.; YUSSOF, S.. A review of life cycle assessment method for building industry. Renewable and Sustainable Energy Reviews, v.45, p.244-248, 2015. DOI: https://doi.org/10.1016/j.rser.2015.01.043

REPELE, M.; BAZBAURES, G.. Life cycle assessment of renewable energy alternatives for replacement of natural gas in building material industry. Energy Procedia, v.72, p.127-134, 2015. DOI: https://doi.org/10.1016/j.egypro.2015.06.018

SILVA, B. V.. Construção de ferramenta para Avaliação do Ciclo de Vida de Edificações. Dissertação (Mestrado em Energia) - Universidade de São Paulo, São Paulo, 2013. DOI: https://doi.org/10.11606/d.86.2013.tde-15052013-103100 
SOUST-VERDAGUER, L. C.; GARCÍA-MARTINEZ, A..

Simplification in life cycle assessment of single-family houses: a review of recent developments. Building and

Environment, v.103, p.215-227, 2016. DOI:

https://doi.org/10.1016/j.buildenv.2016.04.014

TAVARES, S. F.. Metodologia de análise do ciclo de vida energético de edificações residenciais brasileiras. Tese (Doutorado em Engenharia Civil) - Universidade Federal de Santa Catarina, Florianópolis, 2006
USGBC. United States Green Building Concil. LEED for New Construction \& Major Renovations. Green Building Rating System. Version 2.2. Washington: USGBC, 2005.

VINHAL, L. D.. Estudo de indicadores ambientais de blocos cerâmicos com base em avaliação do ciclo de vida, considerando o contexto brasileiro. Dissertação (Mestrado em Construção Civil) - Universidade Federal de São Carlos, São Carlos, 2016.

YIN, R. K.. Estudo de caso: planejamento e método. 2 ed. Porto Alegre: Bookman, 2001.

A CBPC - Companhia Brasileira de Produção Científica (CNPJ: 11.221.422/0001-03) detém os direitos materiais desta publicação. Os direitos referem-se à publicação do trabalho em qualquer parte do mundo, incluindo os direitos às renovações, expansões e disseminações da contribuição, bem como outros direitos subsidiários. Todos os trabalhos publicados eletronicamente poderão posteriormente ser publicados em coletâneas impressas sob coordenação da Sustenere Publishing, da Companhia Brasileira de Produção Científica e seus parceiros autorizados. Os (as) autores (as) preservam os direitos autorais, mas não têm permissão para a publicação da contribuição em outro meio, impresso ou digital, em português ou em tradução. 